\title{
Fair Hair
}

National Cancer Institute

\section{Source}

National Cancer Institute. Fair Hair. NCI Thesaurus. Code C115219.

A human hair color characterized by low levels of eumelanin. 